Louisiana State University

LSU Digital Commons

Faculty Publications

Department of Biological Sciences

$10-1-2013$

\title{
Social descent with territory loss causes rapid behavioral, endocrine and transcriptional changes in the brain
}

\author{
Karen P. Maruska \\ Stanford University \\ Lisa Becker \\ Stanford University \\ Anoop Neboori \\ Stanford University \\ Russell D. Fernald \\ Stanford University
}

Follow this and additional works at: https://digitalcommons.Isu.edu/biosci_pubs

\section{Recommended Citation}

Maruska, K., Becker, L., Neboori, A., \& Fernald, R. (2013). Social descent with territory loss causes rapid behavioral, endocrine and transcriptional changes in the brain. Journal of Experimental Biology, 216 (19), 3656-3666. https://doi.org/10.1242/jeb.088617

This Article is brought to you for free and open access by the Department of Biological Sciences at LSU Digital Commons. It has been accepted for inclusion in Faculty Publications by an authorized administrator of LSU Digital Commons. For more information, please contact ir@lsu.edu. 


\title{
RESEARCH ARTICLE
}

\section{Social descent with territory loss causes rapid behavioral, endocrine and transcriptional changes in the brain}

\author{
Karen P. Maruska*, Lisa Becker, Anoop Neboori and Russell D. Fernald \\ Department of Biology, Stanford University, 371 Serra Mall, Stanford, CA 94305, USA \\ *Author for correspondence at present address: Department of Biological Sciences, Louisiana State University, Baton Rouge, LA 70803, USA \\ (kmaruska@Isu.edu)
}

\begin{abstract}
SUMMARY
In social species that form hierarchies where only dominant males reproduce, lower-ranking individuals may challenge higherranking ones, often resulting in changes in relative social status. How does a losing animal respond to loss of status? Here, using the African cichlid fish Astatotilapia burtoni, we manipulated the social environment, causing males to descend in rank, and then examined changes in behavior, circulating steroids and immediate early gene (IEG) expression (cfos, egr-1) in micro-dissected brain regions as a proxy for neuronal activation. In particular, we examined changes in the conserved 'social behavior network' (SBN), a collection of brain nuclei known to regulate social behaviors across vertebrates. Astatotilapia burtoni has rapidly reversible dominant-subordinate male phenotypes, so that within minutes, descending males lost their bright body coloration, switched to submissive behaviors and expressed higher plasma cortisol levels compared with non-descending and control males. Descending males had higher IEG expression throughout the SBN, but each brain region showed a distinct IEG-specific response in either cfos or egr-1 levels, but not both. Overall, SBN IEG patterns in descending males were distinctly different from the pattern observed in males ascending (subordinate to dominant) in social status. These results reveal that the SBN rapidly coordinates the perception of social cues about status that are of opposite valence, and translates them into appropriate phenotypic changes. This shows for the first time in a non-mammalian vertebrate that dropping in social rank rapidly activates specific socially relevant brain nuclei in a pattern that differs from when males rise to a higher status position.
\end{abstract}

Key words: Astatotilapia burtoni, cfos, defeat, immediate early gene, social behavior network, status loss, subordinate, teleost.

Received 21 March 2013; Accepted 10 June 2013

\section{INTRODUCTION}

How does an animal respond to dropping in social rank? Dominance hierarchies are a central organizing mechanism for animal societies, and status can regulate access to resources and impact health, survival and reproduction. For species with dominance hierarchies in which reproductive success is linked to status, social defeat has both immediate and long-lasting effects on the behavior and physiology of losing individuals. In all species, social defeat is a profound stressor that induces adaptive coping mechanisms, including a switch to more submissive behaviors and activation of the hypothalamic-pituitary-adrenal [or hypothalamic-pituitaryinterrenal (HPI) in fishes] axis, resulting in elevated circulating stress hormone levels (Sapolsky, 2005; Tamashiro et al., 2005). Social subordination is also associated with distinct neuropeptide and monoaminergic activity in discrete brain regions from fishes through mammals, suggesting some common themes for stress-coping styles among all vertebrates (Neumann, 2002; Øverli et al., 2007). Acute and chronic social defeat in mammals also differentially activates brain regions involved in processing social salience (KollackWalker et al., 1997; Kollack-Walker et al., 1999; Martinez et al., 2002; Morrison et al., 2012). For example, resident-intruder paradigms in rats, mice and hamsters have shown region-specific activation of brain nuclei from the forebrain to the brainstem following social defeat stress (Martinez et al., 2002). In humans, fMRI studies show activation of different brain regions when subjects process social superiority versus inferiority, suggesting that specific cortical areas mediate neural encoding of hierarchical rank (Zink et al., 2008). Aside from a few select mammals, however, little is known about which brain regions are involved in the perception and processing of a decline in social status. Understanding general principles of vertebrate responses to changes in social rank will help identify conserved neural circuitry that has evolved to generate adaptive behavioral decisions and consequent phenotypic change.

Social behaviors in vertebrates are controlled by evolutionarily conserved neural circuits that evaluate the salience of cues from different contexts and regulate behavioral outcomes. The 'social behavior network' (SBN) is one designated network comprised of a core collection of six brain nuclei, or nodes (lateral septum, medial extended amygdala/bed nucleus of the stria terminalis, preoptic area, anterior hypothalamus, ventromedial hypothalamus and midbrain periaqueductal gray/tegmentum), that are reciprocally connected, express sex-steroid receptors and are implicated in the regulation of social behaviors such as parental care, aggression, mating and sexual behaviors, response to social stressors, and communication (Newman, 1999; Goodson, 2005). The SBN was originally described in mammals (Newman, 1999), but homologous regions exist in fishes (Goodson and Bass, 2002; Goodson, 2005), amphibians (Goodson, 2005), reptiles (Crews, 2003) and birds (Goodson, 2005; Goodson and Kabelik, 2009), and it has been hypothesized to be part of a larger 'social decision-making' network that regulates social interactions across vertebrates (O'Connell and Hofmann, 2011; 
O'Connell and Hofmann, 2012). To understand how the SBN responds under varying social conditions, immediate early genes (IEGs), such as the transcription factors cfos and egr-1 (also known as zenk, zif268, krox-24, ngfi- $a$ and tis8), are widely used indicators of region-specific neural activation (Burmeister et al., 2005; Robinson et al., 2008). IEGs reflect the relationship between extracellular signals and changes in gene expression, so that measuring their expression levels can reveal how and which specific brain regions respond to novel stimuli. We experimentally induced a change in social status in a semi-natural situation and measured rapid IEG induction to identify which brain regions, and hence related neural circuitry, respond as an animal perceives changes in its relative position within a dominance hierarchy.

Astatotilapia burtoni (Günther 1894), an African cichlid fish, is an ideal model for assessing how social decline and corresponding loss of territory and reproductive opportunities influences the SBN because males of this species have evolved two distinct and rapidly reversible phenotypes: dominant males, which comprise $\sim 10-30 \%$ of the population, are brightly colored, defend territories, and actively court and spawn with females; and subordinate males, which are drably colored, similar to females, do not hold territories, and are reproductively suppressed (Fernald, 2009; Maruska and Fernald, 2014). Importantly, the social and physical environment of this species is dynamic, with frequent loss and gain of territory ownership (Fernald and Hirata, 1977). By manipulating the social environment, we can experimentally induce social transitions in either direction to test specific hypotheses about the behavioral and physiological changes that occur during natural transitions. Several studies in $A$. burtoni have measured changes associated with rapid social ascent from suppressed male to reproductively active territory holder (White et al., 2002; Burmeister et al., 2005; Maruska and Fernald, 2010a; Maruska and Fernald, 2011a; Maruska and Fernald, 2011b; Maruska et al., 2011; Kustan et al., 2012), but there is limited information on the effects of social descent in this species (Fox et al., 1997; Hofmann and Fernald, 2000; White et al., 2002; Parikh et al., 2006a).

We developed a paradigm, based on natural behavior and ecological context, to induce social descent in $A$. burtoni males to identify behavioral, endocrine and neural responses to territory loss concomitant to a decline in rank. This is the first study using IEGs as a proxy for neural activation to analyze how the brain, and the SBN in particular, responds to social descent. Social descent, or dropping in rank, is much more than losing a fight; it is also loss of social position, territory ownership and reproductive opportunities. As such, it signals the start of reproductive suppression characteristic of the subordinate male phenotype. Our work therefore provides novel information on how individuals rapidly adjust their behavior, hormone profile and brain activation patterns when falling in rank. Importantly, this also represents an example of social decline in fishes, which supplements related studies on neural correlates of social subordination in other teleosts such as salmonids (Overli et al., 1999; Gilmour et al., 2005) and zebrafish (Larson et al., 2006; Filby et al., 2010). These studies in fishes, the largest and most diverse group of vertebrates, with $>30,000$ species, provides crucial and needed comparative data to understand the evolution of coping mechanisms in response to social descent. We compare these results of social descent with our previous analyses of social ascent (subordinate to dominant) (Maruska et al., 2013) in which males gain a territory and reproductive opportunities to understand how the brain coordinates the perception of similar highly salient cues of opposite social valence. Dominance hierarchies and frequent changes in relative status position are widespread in the animal kingdom, so our results have important implications for understanding the evolution of neural mechanisms that mediate status transitions across all taxa.

\section{MATERIALS AND METHODS Animals}

Adult $A$. burtoni derived from wild-caught stock in Lake Tanganyika, Africa, were laboratory-bred in aquaria under environmental conditions that mimic their natural habitat $\left(28^{\circ} \mathrm{C}\right.$; $\mathrm{pH} 8.0 ; 12 \mathrm{~h}: 12 \mathrm{~h}$ light:dark with full-spectrum illumination). Aquaria contained gravel-covered bottoms with halved terracotta pots to serve as shelter and spawning territories. Fish were fed cichlid pellets and flakes (AquaDine, Healdsburg, CA, USA) each morning. All experimental procedures were approved by the Stanford Administrative Panel for Laboratory Animal Care.

\section{Experimental setup and behavioral analysis}

To measure how males respond behaviorally and physiologically to social descent in the short-term, we established a paradigm where a resident dominant male was evicted from his territory by an intruder and forced to become subordinate. As a comparison, we also tested resident dominant males that successfully defended and maintained their territories against an intruder (Fig. 1). For all conditions, subject resident males were chosen from community tanks where they held a territory and performed typical dominance behaviors for several days (3-5 days) prior to use in experiments. The subject male was then placed in the center compartment of an experimental tank with two females and a shelter, where he established a territory and acclimated for $48 \mathrm{~h}$. During this acclimation period, the subject male was allowed to interact with a small community of fish (one dominant male, two females) across a clear barrier on the left, while the right compartment that held the intruder fish was blocked with an opaque barrier.

On the day of the experiment, subject males were randomly assigned to face a larger, smaller or no intruder, which resulted in one of the three different experimental groups described below: descending (faced a larger intruder), non-descending (faced a smaller intruder) or control (no intruder). The subject male was first filmed (Canon FS20 digital camcorder) in the acclimation setup for $5 \mathrm{~min}$ (pre-trial period), and then an opaque barrier was inserted to block the small community of conspecifics in the left compartment and an intruder fish was introduced into the central subject male's compartment. To ensure that the intruder evicted the resident from his territory and forced him to descend in status (descending condition), we used dominant male intruders that were $5-10 \mathrm{~mm}$ longer [intruder standard length $(\mathrm{SL})=57.2 \pm 1.05 \mathrm{~mm}$ ] than the resident male. For the non-descending condition, we used dominant male intruders that were $2-6 \mathrm{~mm}$ shorter in SL $(51.5 \pm 2.51 \mathrm{~mm})$ than the resident, which resulted in the resident male keeping his territory and forcing the intruder into a subordinate position. In procedural control trials, the protocol was identical, including placement of the opaque barrier to block the conspecifics on the left, except that an empty net was dipped into the subject male's compartment without introduction of any intruder fish. Importantly, in all three conditions, the subject males were resident in their compartments and were not moved, unlike in previous studies (White et al., 2002; Parikh et al., 2006a), making it more representative of natural circumstances and less likely to cause background IEG activation as a result of fish movement. This paradigm mimics the natural scenario of an intruder rival male challenging a resident dominant male and evicting him from his territory, and was designed to specifically test how a territory-holding male would respond to the loss of a territory (i.e. 

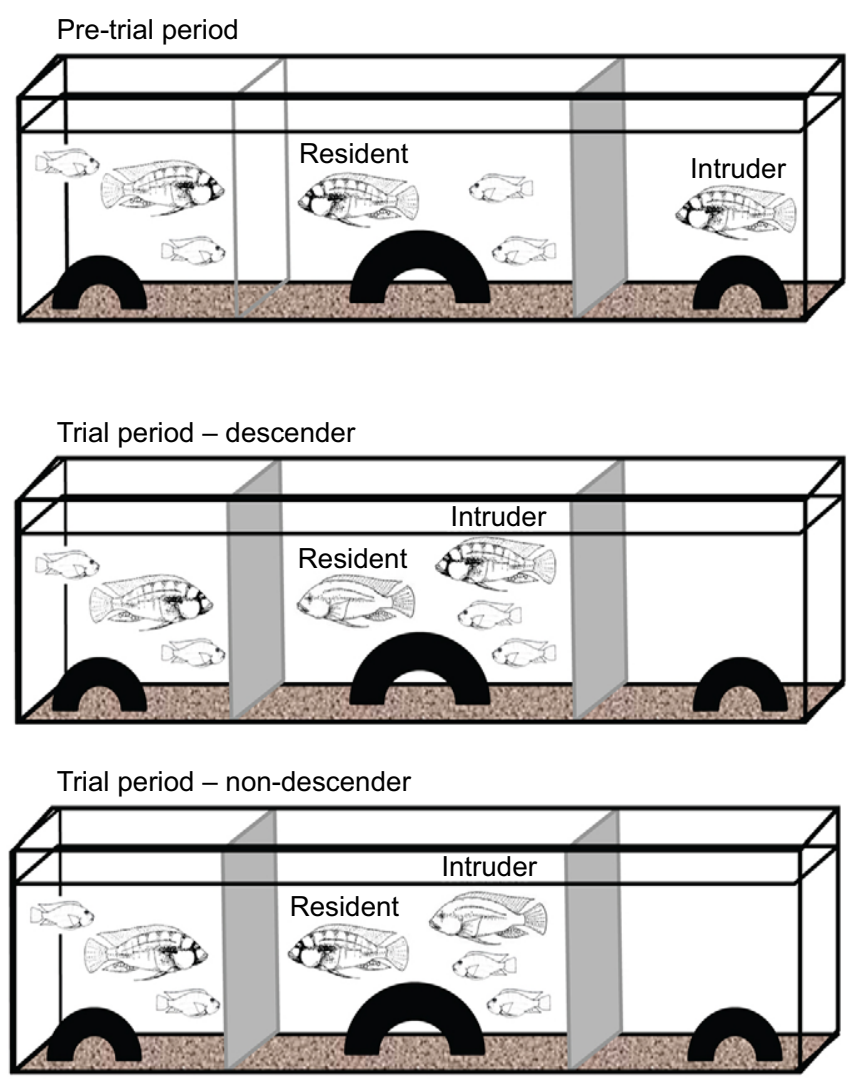

Fig. 1. Schematic diagram of the experimental setup. During the pre-trial period (top panel), a resident dominant male was housed with two females in the center compartment and separated from a small community (one dominant male, two females) on the left by a transparent barrier. The intruder was housed in the right compartment behind an opaque barrier. At trial onset, an opaque barrier was placed on the left to visually block the community fish, and the intruder was then transferred into the central compartment. Resident males that descended in status (descenders) (middle panel) lost their bright body coloration and performed more submissive behaviors, while the intruder took over the territory and performed dominant behaviors. Resident males that did not descend (nondescenders) (bottom panel) maintained bright coloration and territory ownership while the intruder lost his bright coloration and became subordinate. In procedural control trials (not shown), the barrier was placed on the left to visually block the community fish and a net was dipped into the central compartment but no intruder fish was transferred.

loss of territorial and reproductive opportunities), rather than merely to the loss of a single fight. This scenario also represents the onset of social descent, which begins with eviction from a territory and a switch to submissive behaviors. Following intruder introduction, fish were filmed for 40-45 min for subsequent behavioral analysis (trial period). When one of the males met any two of the following criteria after the initial male-male interaction, that male was considered dominant: (1) entered shelter multiple times within a 1 min period, (2) entered and stayed inside shelter alone for $>10 \mathrm{~s}$, (3) performed any three dominance behaviors within a $1 \mathrm{~min}$ period, or (4) chased or bit the other male fish. In addition, the fish considered subordinate also had to show loss of eye-bar expression and bright body coloration, and perform submissive behaviors such as fleeing or remaining in a subordinate tank location (e.g. corner, surface of water column). The time of descent or non-descent was defined as the time when these dominant-subordinate criteria were met. Thus, residents that maintained their territory and dominance status were designated as non-descenders [SL $=53.2 \pm 1.83 \mathrm{~mm}$, body mass $\left(M_{\mathrm{b}}\right)=4.08 \pm 0.43 \mathrm{~g}$, gonadosomatic index $(\mathrm{GSI})=($ gonad $\left.\operatorname{mass} / M_{\mathrm{b}}\right) \times 100=0.76 \pm 0.05, N=12$ ], while residents that lost their territory and assumed a subordinate position were designated as descenders $\left(\mathrm{SL}=51.9 \pm 1.23 \mathrm{~mm}, M_{\mathrm{b}}=3.67 \pm 0.27 \mathrm{~g}, \mathrm{GSI}=0.81 \pm 0.48\right.$, $N=12$ ). Resident males were then euthanized $30 \mathrm{~min}$ after they descended (descenders) or maintained their territory (nondescenders). Procedural control males ( $\mathrm{SL}=51.0 \pm 1.80 \mathrm{~mm}$, $M_{\mathrm{b}}=3.32 \pm 0.35 \mathrm{~g}, \mathrm{GSI}=0.85 \pm 0.06, N=12$ ) were euthanized at time points to match those of descending and non-descending fish. There was no difference in SL, $M_{\mathrm{b}}$ or GSI among descenders, nondescenders and controls (ANOVA, $P>0.30$ ), indicating that males in all groups were of similar size, age and reproductive state.

We quantified dominance behaviors (courtship quivers, leads, tail waggles, shelter entries, lateral displays, chases, bites, frontal threats and border fights) (Fernald, 1977) and submissive behaviors (fleeing) performed by each individual for the $5 \mathrm{~min}$ pre-trial period and during the $40-45 \mathrm{~min}$ trial period. For analyses, behavior rates were compiled into $5 \mathrm{~min}$ bins. Because absolute behavior rates vary among individual fish, we also calculated the dominance index $[\mathrm{DI}=($ sum of reproductive and territorial behaviors-subordinate behaviors)/time analyzed (in $\mathrm{min}$ )] for each individual male and compared the mean percentage change in dominance index between pre-trial and trial periods among groups.

\section{Tissue preparation, microdissection and quantitative reverse transcription PCR}

Methods for tissue preparation, microdissection and quantitative reverse transcription PCR (qRT-PCR) were identical to those used previously (Maruska et al., 2013) and are only briefly described here. Fish were anesthetized in ice-cold tank water and SL and $M_{\mathrm{b}}$ were measured. Blood samples were collected with capillary tubes from the caudal vein and centrifuged for $10 \mathrm{~min}$ at $6010 \mathrm{~g}$, and plasma was removed and stored at $-80^{\circ} \mathrm{C}$ until assayed. Fish were euthanized by swift cervical transection and brains were removed, embedded in mounting medium (Neg50, Thermo Scientific, Waltham, MA, USA), rapidly frozen on dry ice, and stored at $-80^{\circ} \mathrm{C}$ until sectioning. Pituitaries were also removed, frozen and stored at $-80^{\circ} \mathrm{C}$. Testes were removed and weighed to calculate GSI.

Brains were sectioned in the coronal plane at $300 \mu \mathrm{m}$ on a cryostat and sections were collected onto charged slides (Superfrost Plus, VWR, Radnor, PA, USA) and stored at $-80^{\circ} \mathrm{C}$. To microdissect specific brain regions, slides were placed on a frozen stage (BFS30MP, Physitemp, Clifton, NJ, USA), viewed under a dissection microscope, and tissue was collected with a modified $23 \mathrm{G}$ needle (inner diameter $\sim 390 \mu \mathrm{m}$ ) attached to a syringe. Brain atlases from A. burtoni (Fernald and Shelton, 1985; Burmeister et al., 2009) and other fish species (Munoz-Cueto et al., 2001) were used to target brain regions that were centered on the following nuclei [proposed putative mammalian homologs are given in parentheses and are based on consensus from the following reviews (Wullimann and Mueller, 2004; Goodson, 2005; O'Connell and Hofmann, 2011; Maximino et al., 2013)]: lateral part of the dorsal telencephalon (Dl; sampled in ventral region, Dlv) (hippocampus, medial pallium); medial part of the dorsal telencephalon (Dm) (pallial amygdala, ventral pallium); ventral nucleus of the ventral telencephalon ( $\mathrm{Vv})$ (septal formation in part); supracommissural nucleus of the ventral telencephalon (Vs; sampled in Vsm region) (extended amygdala: medial amygdala, central amygdala, bed nucleus of the stria terminalis); preoptic area (POA) (preoptic area); ventral tuberal nucleus (VTn) (anterior hypothalamus in part); anterior tuberal nucleus (ATn) (ventromedial hypothalamus in part); and corpus 
cerebellum (Ce) (sampled in the granule cell layer, $\mathrm{CCeG}$ ). These brain regions include the SBN (with the exception of the periaqueductal gray, which was not sampled) and others (Dl, Ce), and were chosen to match those collected in our previous study on social ascent (Maruska et al., 2013). It is also important to mention that the putative mammalian homologies in the teleost brain are not yet fully resolved, and more detailed descriptions of the regions we sampled can be found in Maruska et al. (Maruska et al., 2013). Because of technical limitations of microdissection, tissue collection was centered on these nuclei and standardized across individuals, but some nuclei likely also contained portions of surrounding regions [see Maruska et al. (Maruska et al., 2013) for further details on microdissected nuclei]. Tissue was collected directly into lysis buffer (RNeasy Micro Kit, Qiagen, Valencia, CA, USA), frozen on dry ice and stored at $-80^{\circ} \mathrm{C}$ until RNA isolation.

Total RNA was isolated from homogenized pituitaries and microdissected brain tissue following standard methods (RNeasy Plus Micro Kit, Qiagen) described previously (Maruska and Fernald, 2010c; Maruska et al., 2011), reverse transcribed to cDNA (iScript cDNA Synthesis Kit, Bio-Rad Laboratories, Hercules, CA, USA) and diluted 1:3 prior to use as a template for qRT-PCR reactions. qRT-PCR was used to measure mRNA levels of two IEGs, egr-1 and $c f o s$, and two reference genes, $g 3 p d h$ and $18 s r R N A$. Primers were commercially synthesized (Invitrogen, Carlsbad, CA, USA) and were identical to those used in previous studies (Burmeister and Fernald, 2005; Zhao and Fernald, 2005; Burmeister et al., 2007; Maruska and Fernald, 2010b). qRT-PCR was performed using a previously described protocol (Maruska and Fernald, 2010c) with $20 \mu \mathrm{l}$ duplicate reactions (SSoFast EvaGreen Supermix, Bio-Rad) run on a Bio-Rad CFX96 qPCR machine.

Reaction efficiencies and cycle thresholds $\left(C_{\mathrm{T}}\right)$ were calculated from the fluorescence readings of individual wells during the reaction using PCR Miner software (Zhao and Fernald, 2005), and the relative amount of mRNA in each sample was normalized to the geometric mean of the two reference genes $(g 3 p d h, 18 s)$ as previously described (Zhao and Fernald, 2005; Maruska et al., 2011). Mean values for $g 3 p d h$ and $18 s$ did not differ among the three male groups for any brain region (ANOVAs, $P>0.05$ ), indicating they are appropriate reference genes for this study (Bustin et al., 2009).

\section{Hormone assays}

Plasma levels of 11-ketotestosterone (11-KT), 17 $\beta$-estradiol $\left(\mathrm{E}_{2}\right)$ and cortisol were measured using commercially available Enzyme ImmunoAssay (EIA) kits (Cayman Chemical, Ann Arbor, MI, USA) as previously described and validated for this species (Maruska and Fernald, 2010c). For 11-KT and $E_{2}$ assays, plasma samples were extracted with ethyl ether (extraction efficiency 87-91\%) and reconstituted in assay buffer (1:60 dilution). Cortisol assays were run on non-extracted plasma samples (1:80 dilution). EIA kit protocols were strictly followed, plates were read at $405 \mathrm{~nm}\left(\mathrm{UV}_{\max }\right.$ Microplate Reader, Molecular Devices, Sunnyvale, CA, USA) and steroid concentrations were determined based on standard curves. All samples were assayed in duplicate for each hormone, and intra-assay coefficients of variation were $7.1,9.8$ and $10.5 \%$ for $11-\mathrm{KT}, \mathrm{E}_{2}$ and cortisol, respectively.

\section{Statistical analyses}

Comparisons of GSI, SL, $M_{\mathrm{b}}$, circulating steroids and DI among experimental groups were made with one-way ANOVA followed by Student-Newman-Keuls (SNK) tests for multiple comparisons. Behavioral comparisons were made with generalized linear model repeated-measures ANOVA (GLZM) with time as the within- subjects repeated factor and behavior category (dominant and subordinate) as the between-subjects factor. To test for differences in brain IEG levels among groups, we used GLZM for each IEG, with brain region as the repeated within-subject factor and experimental group as the between-subject factor, followed by pairwise comparisons. To determine the IEG pattern of brain expression that best predicted group status (control, non-descender, descender), we also used a linear discriminant function analysis (LDA) test on both egr-1 and cfos levels in all brain regions. LDA analysis combines (weights) all of the input variables to produce a single new composite variable, or discriminant score, which identifies the input variables that contribute most to differentiating amongst the three experimental groups. Factor loadings above 0.30 were considered important for interpreting group membership. Statistical analyses were performed with SPSS 19 (IBM, Armonk, NY, USA).

\section{RESULTS \\ Behavior}

Subject resident males all showed similar dominance behaviors (ANOVA, $F_{2,33}=2.55, P=0.10$ ), and no subordinate behaviors, during the pre-trial period (Fig. 2). In all groups, there was an initial decrease in dominance behaviors during minutes 5-9, due to the placement of the opaque barrier and introduction of the intruder, which caused a temporary disturbance in the tank, followed by a several minute recovery before the fish resumed their behaviors. Resident males that were evicted from their territories all rapidly turned off their eye-bars and their bright body coloration faded within minutes as they switched to performing more subordinate behaviors and fewer dominance behaviors (GLZM, between-subjects $F_{1,22}=32.59, P<0.001$; Fig. $2 \mathrm{~A}$ ). The latency to descend (time between intruder introduction and descent criteria met) was $11.3 \pm 1.72 \mathrm{~min}$ (mean \pm s.e.m.), during which time the mean rate of dominance behaviors decreased from $>5$ behaviors $\mathrm{min}^{-1}$ in the pretrial period to $<1$ behavior min $^{-1}$. Non-descending fish maintained a similar level of dominance behaviors before and after the intruder was introduced, with few to no subordinate behaviors performed during the trial (GLZM, between-subjects $F_{1,22}=142.43, P<0.001$; Fig. 2B). Latency to meet the criteria for non-descent was $7.17 \pm 0.91 \mathrm{~min}$ (mean \pm s.e.m.). Control fish also continued to display dominance behaviors and no subordinate behaviors during the trial (GLZM, between-subjects $F_{1,22}=23.07, P<0.001$ ), but there was a slight decrease in overall behavior rates because without addition of an intruder male, these residents were only interacting with the females during the trial period and therefore were performing primarily reproductive behaviors and not male-male aggressive behaviors (Fig. 2C).

The percentage change in DI between pre-trial and trial periods differed among all three experimental groups (ANOVA, $F_{2,33}=31.73$, $P<0.001$; SNK, $P<0.05$; Fig. $3 \mathrm{~A}$ ). Males that descended in status showed the greatest percent decrease in DI, indicating that they reduced their dominance behaviors and increased their submissive behaviors after introduction of the intruder. Non-descending males showed little change in DI between pre-trial and trial periods, while control fish also showed a decrease in DI because as mentioned above, there was no male-male interaction during the trial in this group.

\section{Circulating steroid hormones}

Circulating cortisol levels were higher in fish that descended in social status compared with both non-descenders and controls (ANOVA, $F_{2,33}=3.79, P=0.033$; SNK, $P<0.05$; Fig. $3 \mathrm{~B}$ ). There was also a negative correlation between cortisol levels and the percent change 

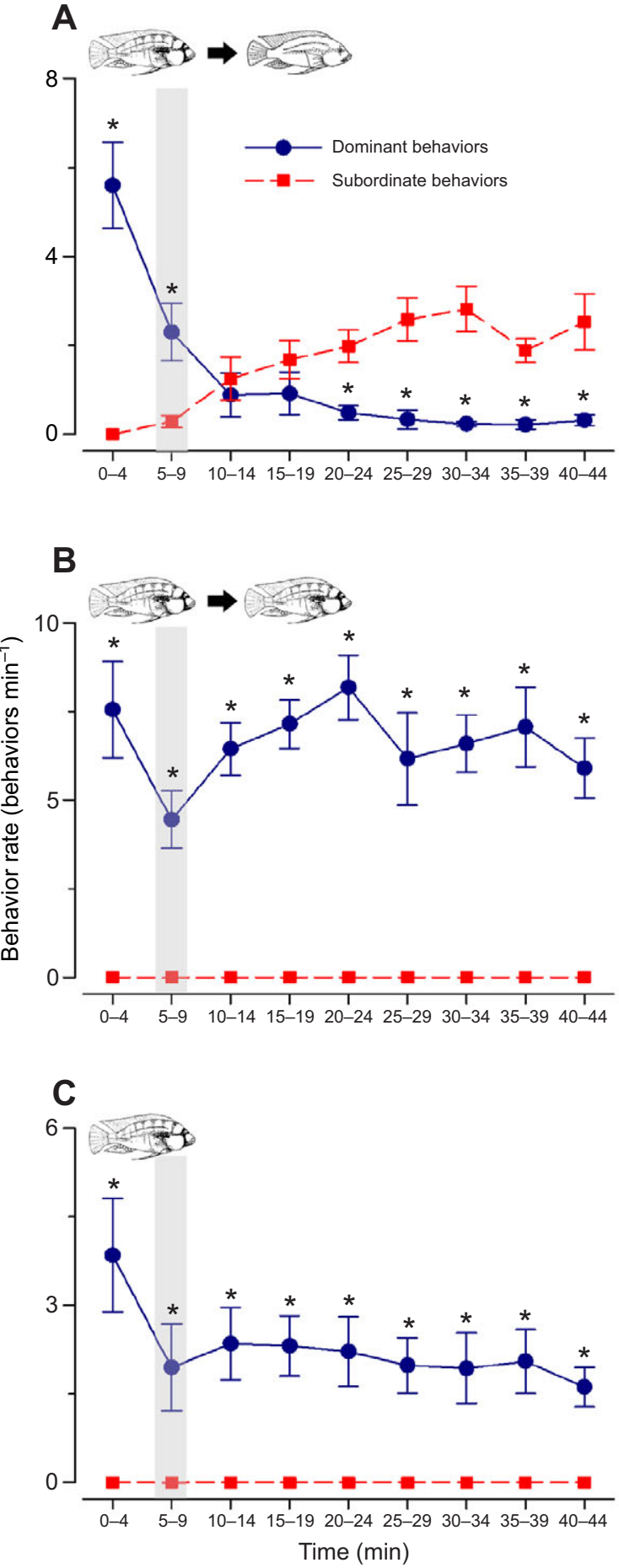

Fig. 2. Behavior rates for descenders (A), non-descenders (B) and controls (C) before and during the experimental trial. Descender resident males decreased their dominance behaviors and increased subordinate behaviors after introduction of an intruder male. Non-descenders and control fish continued to perform dominance behaviors and no subordinate behaviors after the start of the trial. Data are plotted as means \pm s.e.m., compiled into 5 min bins. Dominant behaviors (combined territorial and reproductive) (circles, solid lines) and subordinate behaviors (fleeing) (squares, dashed lines) are plotted at each time point. Minutes 0-4 represent the pre-trial period when the resident was interacting with the small community in the left compartment, and the shaded box at minutes 5-9 indicates placement of the left opaque barrier and introduction of the intruder at minute 5. Asterisks designate statistical differences between dominant and subordinate behaviors within each $5 \mathrm{~min}$ bin $(P<0.05)$. $N=12$ fish per group per time point.
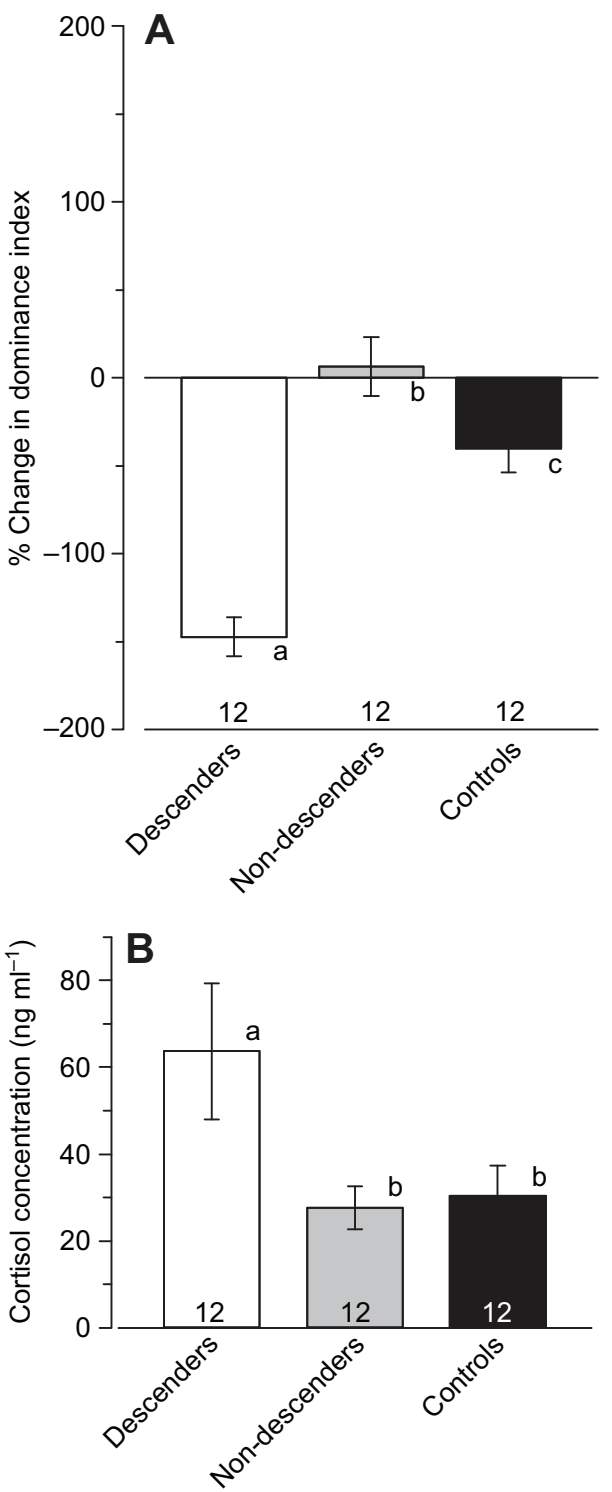

Fig. 3. Percent change in behavioral dominance index and levels of plasma cortisol in descenders, non-descenders and controls. (A) Males that descended in status showed the greatest decrease in dominance index, indicating they performed more subordinate and fewer dominant behaviors during the trial. Non-descenders showed little change in dominance index, while controls showed a slight decrease in dominance index because they lacked interaction with another male during the trial. Data are plotted as the mean \pm s.e.m. percent change in dominance index between pre-trial and trial periods. (B)Descending males had higher plasma cortisol levels compared with males that maintained their territory and dominance status (non-descenders and controls). Data are plotted as means \pm s.e.m. Different letters indicate statistical differences at $P<0.05$. $N=12$ fish per group.

in DI when all fish were examined together (Pearson correlation, $r=0.41, P=0.013$ ), indicating that males showing the greatest change towards more submissive and fewer dominance behaviors had higher cortisol levels. In contrast, there was no difference in circulating levels of $\mathrm{E}_{2}$ (means \pm s.e.m., controls: $55.39 \pm 8.60 \mathrm{ng} \mathrm{ml}^{-1}$; non-descenders: $\quad 55.47 \pm 6.96 \mathrm{ng} \mathrm{ml}^{-1}$; descenders: $\quad 51.96 \pm$ $6.06 \mathrm{ng} \mathrm{ml}^{-1}$ ) or $11-\mathrm{KT}$ (controls: $1.19 \pm 0.25 \mathrm{ng} \mathrm{ml}^{-1}$; non-descenders: $1.95 \pm 0.55 \mathrm{ng} \mathrm{ml}^{-1}$; descenders: $0.92 \pm 0.10 \mathrm{ng} \mathrm{ml}^{-1}$ ) among the three groups (ANOVA, $P>0.10$ ). 

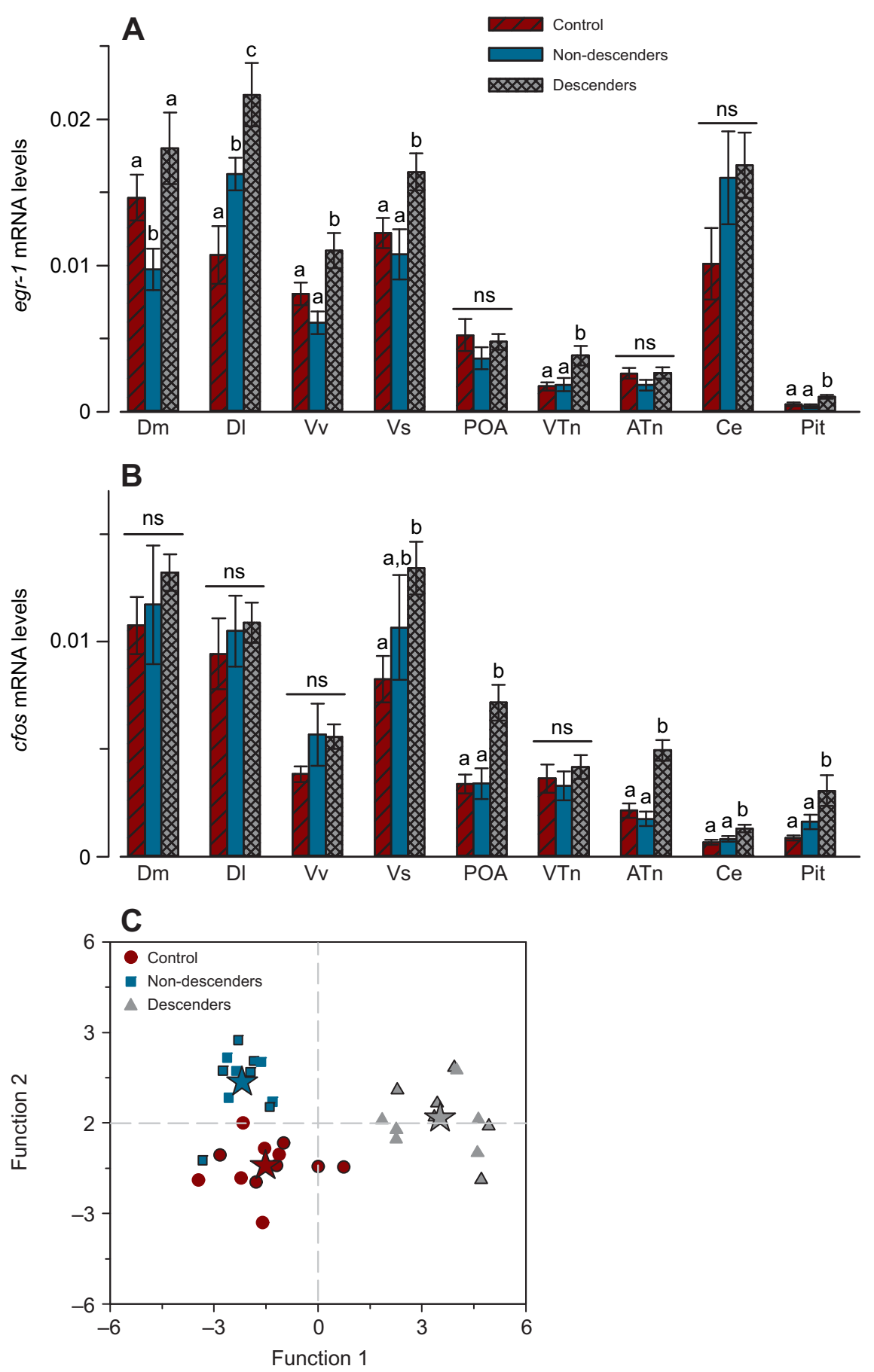

Neural IEG response

Descending males showed distinct nuclei-specific changes in mRNA levels of IEGs compared with non-descending and control males (Fig.4). Levels of egr-1 mRNA were higher in descending males in the Vv, Vs, VTn and Pit compared with both non-descenders and controls (between-subjects, $F=8.63, P=0.001$; SNK, $P<0.05$; Fig. 4A). In the Dm, descending males had higher egr-1 mRNA levels than non-descenders $(P=0.005)$, but levels did not differ from controls $(P=0.213)$. In the $\mathrm{Dl}$, egr-1 levels differed among all three groups (controls $<$ non-descenders $<$ descenders; $P<0.05$ ). Levels of egr-1 mRNA in the POA, ATn and Ce did not differ among groups $(P>0.05)$.

The pattern of $c f o s$ expression among experimental groups differed from that of egr-l across the various brain regions (Fig. 4B).
Fig. 4. Social descent caused immediate early genespecific changes within microdissected nuclei of the social behavior network at $30 \mathrm{~min}$. Egr-1 (A) and cfos (B) mRNA levels are normalized to the geometric mean of the reference genes $18 \mathrm{~s} r R N A$ and $g 3 p d h$, and are plotted as means \pm s.e.m. ATn, anterior tuberal nucleus; Ce, cerebellum; DI, lateral part of the dorsal telencephalon; Dm, medial part of the dorsal telencephalon; Pit, pituitary; POA, preoptic area; Vs, supracommissural nucleus of the ventral

telencephalon; VTn, ventral tuberal nucleus; Vv, ventral nucleus of the ventral telencephalon. Different letters indicate significant differences among groups at $P<0.05$ (ns, not significant). (C) Linear discriminant function analysis of egr-1 and cfos levels in all brain regions. The significant function 1 was most heavily loaded by cfos levels in the POA and ATn, which represent the two input variables that best classify descending males (triangles) as a separate group from non-descending (squares) and control (circles) groups (note the separation of descending individuals from non-descending and controls along the function $1 x$-axis). Function 2 was not statistically significant (note the overlap among all three groups along the function $2 y$-axis), but was most heavily loaded by egr-1 levels in the Dm and DI, suggesting that these two variables came close to classifying nondescending males as separate from control individuals. Discriminant scores for each individual are plotted and stars represent the centroid of each classified group. $N=12$ fish per group. 


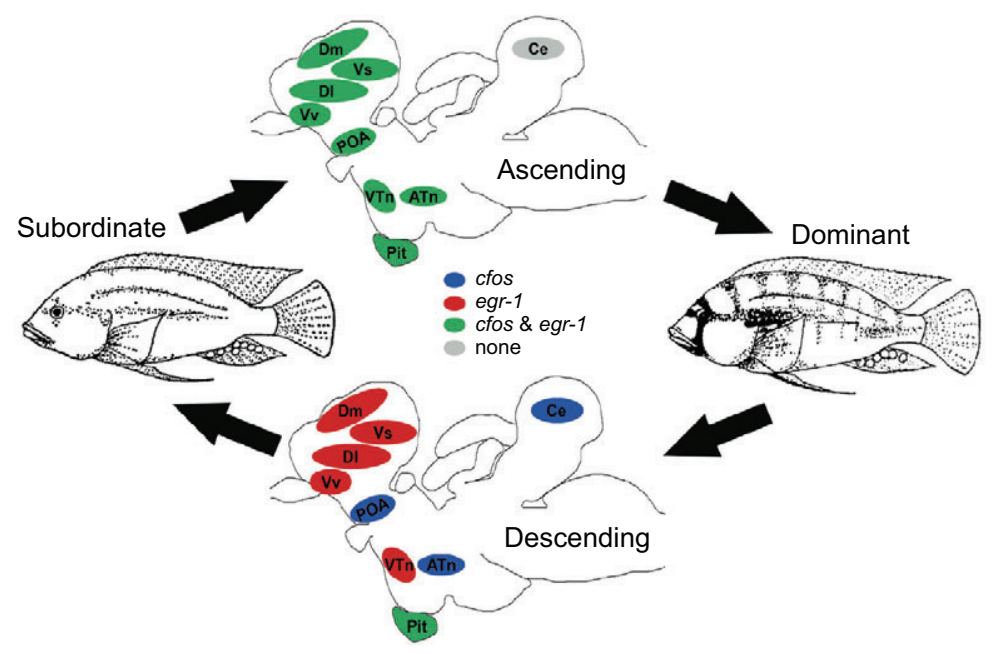

Fig. 5. Differential expression patterns of immediate early genes (IEGs) in the brain of ascending and descending male $A$. burtoni. In ascending males, all SBN nuclei showed coincident higher mRNA levels of both cfos and egr-1 (green) compared with stable status controls. In descending males, however, only egr-1 (red) or cfos (blue) was higher within a specific nucleus, with the exception of the pituitary that had higher levels of both IEGs. Ascending male data are from Maruska et al. (Maruska et al., 2013). Elevated IEG levels depicted here for descending males are those that differed from non-descending male levels only. Locations of each nucleus within the sagittal fish brain are depicted to minimize overlap and are therefore only approximate. See Fig. 4 legend for abbreviations.

contribute most to differentiating amongst the three experimental groups. In other words, this statistical analysis assessed whether our a priori experimental groupings (non-descending, descending, control) could be predicted solely from the quantitative IEG expression data that were measured. This LDA of both IEGs in all brain regions revealed a single significant function (function 1, $\left.\chi^{2}=69.86, P=0.001\right)$ that explained $83.7 \%$ of the total variance (Fig. 4C). Function 1 was most heavily loaded by cfos in the ATn and POA, meaning that the twofold higher levels of $c f o s$ expression in these two brain regions in descenders are the best predictor variables for distinguishing descending males (group centroid=3.52) from non-descending $(-2.19)$ and control $(-1.52)$ groups (note the separation of descending individuals from non-descending and controls along the function $1 x$-axis in Fig. 4C). This LDA correctly classified $100 \%$ of descending males, $90.9 \%$ of non-descending males and $91.7 \%$ of control males (overall 94.3\%), all of which exceed the value for group classification based on chance alone (33.3\%). Although function 2 was not significant $(P>0.05$; note the overlap among all three groups along the function $2 y$-axis in Fig. 4C), meaning there were no variables along this axis that were statistically predictive of separate group classifications, this function was most heavily loaded by egr-1 levels in the Dm and Dl, which separated non-descenders from controls.

The overall pattern of IEG expression within the SBN observed here during social descent differed from that measured in our previous study on social ascent (Maruska et al., 2013) (Fig. 5). With the exception of the pituitary gland where social descent induced elevations in both egr-1 and cfos, each brain region in descending males showed $\leq 2$-fold higher levels in either egr-1 or cfos mRNA, but not both, compared with non-descending and control males. In contrast, males ascending in social status showed a more dramatic increase ( 2- to 6-fold) of both egr-1 and cfos mRNA levels in every SBN nucleus compared with stable subordinate and dominant animals.

\section{DISCUSSION}

How do animals respond to a fall in social status, which has such crucially important implications for survival and future reproductive success? Although this information is relevant to all vertebrates that exist in social societies, including humans, we know little about how different vertebrate groups respond to a change in rank. This is particularly true for fishes, the largest and most diverse vertebrate group that comprises more than half of living vertebrates, where information on how distinct brain nuclei respond to an individual's decline in social status is limited (Winberg et al., 1997; Overli et al., 1999).

Here, we discovered that within $30 \mathrm{~min}$ of a natural social decline by male $A$. burtoni, individuals lost their bright body coloration, switched from dominant to submissive behaviors, and had higher plasma levels of the stress hormone cortisol. These descending males also had higher levels of either cfos or egr-1 in conserved brain regions associated with processing of social information compared with non-descending males. This IEG activation pattern suggests that when males perceive an unfavorable change in their relative social position, not only are these social brain regions activated, but multiple downstream gene pathways are also likely initiated within each brain nucleus. Collectively, this rapid behavioral, endocrine and transcriptional response to a decline in social rank is likely part of a complex coping mechanism to quickly minimize injury from aggressive attacks by other males, promote survival and ensure future reproductive opportunities. To our knowledge, this is the first study to examine neural activation via IEG expression of the SBN in response to social defeat, territory loss and status transition in a non-mammalian model, and it extends our understanding of how the brain mediates social stress-coping behaviors in vertebrates.

\section{Neural IEG response}

The two different IEGs $c$ fos and egr- 1 showed distinct activation patterns within each brain region in descending male $A$. burtoni. That is, in response to identical stimulus conditions, these two IEGs reacted differently within each sampled brain area. The higher IEG levels in descending males compared with non-descending males reflect quick transcriptional changes in specific social nuclei of the brain in response to falling in rank. It is relevant to keep in mind that the protein products of IEGs are transcription factors that can either inhibit or promote the expression of downstream target genes, meaning that increased $c f o s$ or egr-1 expression could reflect inhibition or excitation of specific neuronal circuitry within each nucleus. It is also important to note that the brain regions with higher IEG expression in descending fish are similar to those activated during social defeat in mammals (Kollack-Walker et al., 1997; Martinez et al., 2002), supporting the hypothesis that the SBN represents important 'core' circuitry for processing social information of different valence. In many taxa, social subordination is associated with increased levels of specific neuropeptides or their receptors (e.g. corticotropin-releasing factor system) and 
monoamines (e.g. serotonin) (Matter et al., 1998; Blanchard et al., 2001; Doyon et al., 2003; Summers et al., 2005; Chen and Fernald, 2008), suggesting that a decline in status may activate neuronal populations involved in stress-coping strategies. The overlap in IEG expression between brain areas involved in processing social stimuli and those involved in the stress response suggest that stress is an integral part of many social interactions. As a result, it is likely that components of the neural circuitry mediating social perception are shared by the stress-coping system. It remains unclear, however, exactly what consequences these IEG-specific changes have on downstream gene transcription and physiological function.

Despite the prevalent use of IEG induction for functional brain mapping across taxa, little is known about which downstream genes are influenced by these different transcription factors, including how stimulus-transcription coupling occurs. cFos protein, and other members of its family (Fra-1, Fra-2, FosB), dimerize with members of the Jun protein family (c-Jun, JunB, JunD) to form the transcription factor AP-1 (activating protein 1), while Egr-1 is a member of the Cys2His2 subclass of zinc finger motif-containing proteins. In many cases, AP-1 and Egr-family transcription factors are activated in parallel, but they are considered two different 'gateways' to diverse programs of downstream gene expression because they differ in terms of structural properties and regulatory mechanisms, and have discrete DNA recognition sites (PérezCadahía et al., 2011). The IEGs cfos and egr-1 have documented roles in diverse cellular processes such as signal transduction cascades (Pagel and Deindl, 2011), receptor trafficking (McDade et al., 2009), cell proliferation and cell death (Zhou et al., 2007; Gil et al., 2012), synaptic plasticity (Davis et al., 2003) and others (Lee et al., 2004; Bhattacharyya et al., 2013), making it difficult to assign functional relevance to changes in IEG expression levels from heterogeneous tissue samples. However, these IEG roles in basic neuronal plasticity could have crucial implications for functional changes in the neural circuitry mediating social status transitions. Induction of many different IEGs in response to the same stimulus allows for a complex array of transcriptional modifications that includes both induction and repression of late-response genes to alter cellular phenotype and neuron function. A recent genome-wide screen of activity-driven gene expression in mouse hippocampal neurons treated with different chemical stimuli showed that four different plasticity-related transcription factors (CREB, SRF, EGR1, FOS) can regulate similar biological processes, but do so via nonoverlapping downstream gene-expression patterns (Benito et al., 2011). Thus it is possible that within the heterogeneous cell population collected in our samples, the nature of the external stimulus requires activation of one particular IEG over another to achieve the desired changes in target gene expression. The differences in egr- 1 and $c f o s$ levels within a single brain region also suggest that reliance on a single IEG marker for functional activation may be incomplete, and highlights the importance of examining multiple markers. Different combinations of IEGs acting as transcription factors can therefore regulate suites of genes that ultimately transform external stimuli into longer-term changes in gene expression, neuron function and behavior.

Our LDA analysis revealed that males descending in social status are clearly different from non-descending and control males based solely on IEG expression profiles in SBN nuclei. Levels of $c f o s$ in POA and ATn were most important for distinguishing IEG profiles of descending males from non-descending and control groups. This suggests that relative to other $\mathrm{SBN}$ regions, increased cfos expression in the POA and ATn is important during the initial loss of social status in descending males. In both of these brain regions, descending males showed approximately twofold higher expression of cfos compared with non-descending and control males. The ATn of fishes is homologous in part to the ventromedial hypothalamus of mammals, which is involved in the control of aggression (Lin et al., 2011). Therefore, transcriptional changes that alter outputs of aggressive signaling in the ATn could contribute to reduced dominance and increased subordination in descending male $A$. burtoni. Further, increased egr-1 levels in the VTn of descending males may serve a related function, as this homolog of the anterior hypothalamus also plays a role in aggression in other vertebrates (Goodson et al., 2012). The POA is composed of many nuclei with a multitude of functions including regulation of sexual behavior, reproductive physiology, aggression, parental care, stress-coping, energy homeostasis, thermoregulation, sleep and arousal (O'Connell and Hofmann, 2011). In mammals, several POA nuclei show cfos/cFos-induction following stressors, and many genes encoding neuropeptides expressed in the POA (e.g. vasopressin, somatostatin, $\mathrm{GnRH}$ ) have an AP-1 consensus sequence in their regulatory regions, suggesting they are putative targets for cfos regulation (Kovács, 1998). A previous study in A. burtoni showed that males descending in social status had larger somatostatin neurons in the POA compared with socially ascending fish (Hofmann and Fernald, 2000). It is possible, therefore, that increased cfos expression in the POA reflects activation of somatostatin neurons that mediate the reduced growth rates characteristic of the dominant to subordinate transition (Hofmann et al., 1999). Increased cfos levels in the POA of descending males could also be related to activation of the stress axis, as is commonly seen in rodents following acute social defeat (Martinez et al., 2002). Alternatively, there is evidence in several vertebrate taxa that subdivisions of the POA, ATn, VTn and Vs are involved in reproductive behaviors (Newman, 1999; Lin et al., 2011; O'Connell and Hofmann, 2011), suggesting that higher cfos/egr-1 levels in these nuclei of descending males could be related to activation of neurons involved in inhibition of reproductive circuits. It remains to be discovered, however, which cell types within the POA or other nuclei show IEG induction, and the resulting downstream transcriptional outcomes.

Another intriguing result of our study was the minimal IEG differences between non-descending and control males. These two groups were of identical dominant social status, but while the controls experienced only a momentary physical disturbance from the barrier movement (but without an intruder), the non-descenders were also presented with the social challenge of an intruder. Remarkably, this intruder challenge elicited only minimal IEG changes relative to controls: higher egr-1 levels in Dl and lower egr-1 levels in Dm. The LDA group classification of non-descenders and controls was not significant, but function 2 was most heavily loaded on these two variables, suggesting that egr-1 levels in the $\mathrm{Dl}$ and Dm came close to predicting a difference between controls and non-descending males (note the single non-descending individual clustered within the control individuals in Fig. 4C). In mammals, egr-1 is crucial for retrieval of consolidated long-term memories (Bozon et al., 2003), and in fishes, the $\mathrm{Dl}$ is the putative homolog of the hippocampus (O'Connell and Hofmann, 2011; Maximino et al., 2013), where memory consolidation occurs. Thus, higher egr-1 levels in the D1 of non-descenders could indicate activation of memory retrieval circuits required for the social challenge that was not needed in the control situation. In the mammalian amygdala, egr-1 also plays an important role in learning and memory of contextual fear (Malkani et al., 2004; Maddox et al., 2011). In mice, for example, experimental reduction of egr-1 in the lateral amygdala interferes with contextual fear conditioning 
(Malkani et al., 2004), and egr-1 is thought to be involved in both the initial consolidation and subsequent reconsolidation of fear memories (Maddox et al., 2011). The Dm is the putative teleost homolog of the ventral pallial components of the mammalian amygdala, and lower egr-1 levels in non-descending males could facilitate reduced fear conditioning during the intruder interaction, thereby ensuring his continued 'boldness' in future male-male contests. Similarly, the higher levels of egr-1 in the Dm and Dl of descending males could enhance fear conditioning and help consolidate experience memories involved in their switch to subordination as an adaptive coping strategy crucial for survival and future reproductive success.

\section{Behavior}

Resident $A$. burtoni males that were evicted from their territories quickly turned off their eye-bar, a sign of reduced aggressivity. They also lost their bright body coloration, and switched to submissive behaviors such as avoidance, hovering in a corner or at the water surface, and fleeing from aggressive attacks of the intruder. While our experimental paradigm only examined the short-term response to status loss, it is adaptive for these descending males to quickly signal their subordination to the aggressor and switch into 'survival mode'. There is evidence in mammals that rapid adoption of submissive behaviors during hierarchical position changes can occur after watching others (Frischknecht et al., 1982), and a similar form of social learning may occur in A. burtoni (Grosenick et al., 2007). While coloration and behavioral changes that signal submission happen within minutes, physiological changes along the reproductive axis occur over days to weeks, likely as an adaptation to prolong reproductive capacity in anticipation of a future return to dominance (White et al., 2002; Maruska and Fernald, 2011b; Kustan et al., 2012). A previous study also showed that visual cues alone from a larger dominant male are sufficient to cause loss of bright coloration and submissive behaviors in a smaller dominant male (Chen and Fernald, 2011), but other sensory cues may be required for the full physiological suppression characteristic of the subordinate phenotype (Maruska and Fernald, 2010c; Maruska and Fernald, 2012; Maruska et al., 2012).

\section{Circulating steroid hormones}

Plasma cortisol levels in A. burtoni were higher in descending males that were forced to abandon their territory and adopt subordinate behaviors compared with levels in non-descending and control fish. Elevated circulating stress hormones associated with subordinate status occurs in fishes (Fox et al., 1997; Gilmour et al., 2005), reptiles (Summers, 2002) and mammals (Sapolsky, 2005), although in many species, dominant individuals can also have glucocorticoid levels higher than or equivalent to those of subordinates (Creel, 2001; Creel et al., 2013). Cortisol in the bloodstream results from activation of the stress axis in all vertebrates, and serves to direct metabolic energy away from long-term physiological processes such as reproduction and focus it towards shorter-term goals of combating the stressor (McEwen and Seeman, 1999). When the stressor continues over time and becomes chronic, as in male A. burtoni that descend in rank, suppression of the entire reproductive axis can occur. For example, subordinate males have smaller GnRH1 neurons (Davis and Fernald, 1990), lower plasma levels of gonadotropins and sexsteroid hormones (Parikh et al., 2006b; Maruska et al., 2011), and smaller testes (Davis and Fernald, 1990; Maruska and Fernald, 2011b) compared with dominant males. By shunting energy stores away from reproduction, subordinate males can invest more in somatic growth (Hofmann et al., 1999), giving them an advantage when an opportunity to acquire a vacant territory or challenge a current territory holder arises. Interestingly, cortisol levels are also rapidly elevated when male $A$. burtoni rise in social rank (Maruska et al., 2013), suggesting that transitions in either direction trigger a stress response. Similar rapid cortisol elevations following acute social stressors are typical among vertebrates, including in humans (Kirschbaum and Hellhammer, 1989). In many taxa, including fishes, treatment with stress hormones (e.g. cortisol, corticosterone) can either decrease aggressive behaviors or promote submissive behaviors, but the mechanism depends on species, context and time course (Leshner, 1980; Tokarz, 1987; Øverli et al., 2002). Nevertheless, elevation of cortisol during social descent in A. burtoni may facilitate the transition towards reduced aggression and greater submission as part of an adaptive coping strategy.

\section{How do social ascent and descent differ?}

Rise and fall of social position within a dominance hierarchy is common in A. burtoni, and the ability of males to quickly recognize and act on this status transition is crucial for survival and reproduction. While ascent and descent are both forms of social stress, the status transition requires behavioral and physiological changes that are similar, but opposite in direction. For instance, ascending males intensify their bright body coloration, turn on their eye-bar and increase dominance behaviors. In contrast, descending males lose their bright body coloration, turn off their eye-bar and adopt submissive behaviors. However, the timings of these coloration and behavioral changes are similar, such that the mean latency to descend $(11.3 \mathrm{~min})$ does not differ from the latency to ascend (12.7 min) (Maruska and Fernald, 2010a). This suggests that males quickly evaluate their dynamic social environment and appropriately signal this perception to conspecifics within minutes, regardless of whether it is a transition to a superior or inferior position.

The neural IEG response to social descent was distinct from social ascent. During ascent, or a rise in rank, egr-1 and $c f o s$ were both higher within every examined SBN nucleus. In contrast, during descent, either egr-1 or $c f o s$ was higher within a particular brain region. The only exception was the pituitary, where both IEGs were higher in both ascending and descending males, which may represent activation of different cell types depending on the direction of the transition (e.g. ACTH cells and HPI activation during descent versus gonadotrope cells and hypothalamic-pituitary-gonadal axis activation during ascent). These data collectively suggest a complex regulatory system, mediated by a suite of transcription factors, including these IEGs, to translate the animal's perception of the direction of social transition into transcriptional control of lateresponse genes necessary for adaptive phenotypic change. There are likely different combinations of cell types within each nucleus that show increased egr-1 or cfos expression in response to descent versus ascent, depending on the molecular needs of the cell. For example, the telencephalic region Vs shows increased egr-1 levels in both ascending and descending animals (Fig. 5). The Vs of fishes, the putative homolog of the extended central amygdala of tetrapods (Maximino et al., 2013), is a region of high GABA expression with inhibitory circuit connections to other brain regions (Ekström and Ohlin, 1995; Mueller and Guo, 2009). Egr-1 is known to co-localize in GABAergic cells of other species (Pinaud et al., 2004), and therefore, increased egr-1 levels in Vs during descent could activate GABAergic inhibitory circuits, while increased levels during ascent could activate excitatory neurons involved in permissive behavioral circuits. The recent use of $c f o s$ and egr-1 knockout mice has illustrated the broad range of functions attributed to these two 
transcription factors, and how they can both upregulate and downregulate even closely related gene families (Schippert et al., 2009; Ducruet et al., 2011; Benes et al., 2012). Future studies are needed, therefore, to identify which cell types express IEGs in ascending versus descending animals to determine whether there are subpopulations of neurons involved in context-dependent IEGinduced neural responses, and which downstream genes are modified in the service of social rank transitions.

\section{ACKNOWLEDGEMENTS}

We thank members of the Fernald laboratory for helpful discussions during the course of this work, and the reviewers for insightful comments on the manuscript.

\section{AUTHOR CONTRIBUTIONS}

K.P.M., A.N., and R.D.F. designed the study. K.P.M., A.N. and L.B. performed the experiments and collected the data. K.P.M. analyzed the data, and K.P.M., A.N., L.B. and R.D.F. all contributed to writing the paper.

\section{COMPETING INTERESTS}

No competing interests declared.

\section{FUNDING}

This research was funded in part by the National Institutes of Health [NIH grant no. F32NS061431 to K.P.M.; NIH grant no. NS 034950 to R.D.F.] and the National Science Foundation [NSF grant no. IOS-0923588 to R.D.F.]. Deposited in $\mathrm{PMC}$ for release after 12 months.

\section{REFERENCES}

Benes, J., Mravec, B., Krizanova, O., Kvetnansky, R. and Myslivecek, J. (2012). The restructuring of dopamine receptor subtype gene transcripts in c-fos KO mice. Brain Res. Bull. 87, 511-520.

Benito, E., Valor, L. M., Jimenez-Minchan, M., Huber, W. and Barco, A. (2011). cAMP response element-binding protein is a primary hub of activity-driven neuronal gene expression. J. Neurosci. 31, 18237-18250.

Bhattacharyya, S., Fang, F., Tourtellotte, W. and Varga, J. (2013). Egr-1: new conductor for the tissue repair orchestra directs harmony (regeneration) or cacophony (fibrosis). J. Pathol. 229, 286-297.

Blanchard, R. J., McKittrick, C. R. and Blanchard, D. C. (2001). Animal models of social stress: effects on behavior and brain neurochemical systems. Physiol. Behav. 73, 261-271.

Bozon, B., Davis, S. and Laroche, S. (2003). A requirement for the immediate early gene zif268 in reconsolidation of recognition memory after retrieval. Neuron 40,695701

Burmeister, S. S. and Fernald, R. D. (2005). Evolutionary conservation of the egr-1 immediate-early gene response in a teleost. J. Comp. Neurol. 481, 220-232.

Burmeister, S. S., Jarvis, E. D. and Fernald, R. D. (2005). Rapid behavioral and genomic responses to social opportunity. PLoS Biol. 3, e363.

Burmeister, S. S., Kailasanath, V. and Fernald, R. D. (2007). Social dominance regulates androgen and estrogen receptor gene expression. Horm. Behav. 51, 164170

Burmeister, S. S., Munshi, R. G. and Fernald, R. D. (2009). Cytoarchitecture of a cichlid fish telencephalon. Brain Behav. Evol. 74, 110-120.

Bustin, S. A., Benes, V., Garson, J. A., Hellemans, J., Huggett, J., Kubista, M., Mueller, R., Nolan, T., Pfaffl, M. W., Shipley, G. L. et al. (2009). The MIQE guidelines: minimum information for publication of quantitative real-time PCR experiments. Clin. Chem. 55, 611-622.

Chen, C. C. and Fernald, R. D. (2008). Sequences, expression patterns and regulation of the corticotropin-releasing factor system in a teleost. Gen. Comp. Endocrinol. 157, 148-155.

Chen, C. C. and Fernald, R. D. (2011). Visual information alone changes behavior and physiology during social interactions in a cichlid fish (Astatotilapia burtoni). PLoS ONE 6, e20313.

Creel, S. (2001). Social dominance and stress hormones. Trends Ecol. Evol. 16, 491497.

Creel, S., Dantzer, B., Goymann, W. and Rubenstein, D. R. (2013). The ecology of stress: effects of the social environment. Funct. Ecol. 27, 66-80.

Crews, D. (2003). The development of phenotypic plasticity: where biology and psychology meet. Dev. Psychobiol. 43, 1-10.

Davis, M. R. and Fernald, R. D. (1990). Social control of neuronal soma size. J. Neurobiol. 21, 1180-1188.

Davis, S., Bozon, B. and Laroche, S. (2003). How necessary is the activation of the immediate early gene zif268 in synaptic plasticity and learning? Behav. Brain Res. $142,17-30$.

Doyon, C., Gilmour, K. M., Trudeau, V. L. and Moon, T. W. (2003). Corticotropinreleasing factor and neuropeptide $\mathrm{Y}$ mRNA levels are elevated in the preoptic area of socially subordinate rainbow trout. Gen. Comp. Endocrinol. 133, 260-271.

Ducruet, A. F., Sosunov, S. A., Visovatti, S. H., Petrovic-Djergovic, D., Mack, W. J., Connolly, E. S., Jr and Pinsky, D. J. (2011). Paradoxical exacerbation of neuronal injury in reperfused stroke despite improved blood flow and reduced inflammation in early growth response-1 gene-deleted mice. Neurol. Res. 33, 717725.

Ekström, P. and Ohlin, L. M. (1995). Ontogeny of GABA-immunoreactive neurons in the central nervous system in a teleost, gasterosteus aculeatus L. J. Chem. Neuroanat. 9, 271-288.

Fernald, R. D. (1977). Quantitative behavioral observations of Haplochromis burtoni under semi-natural conditions. Anim. Behav. 25, 643-653.

Fernald, R. D. (2009). Social regulation of reproduction: what changes and why? In Hormones, Brain and Behavior, 2nd edn (ed. D. W. Pfaff, A. P. Arnold, S. E. Fahrbach, A. M. Etgen and R. T. Rubin), pp. 683-692. San Diego, CA: Academic Press.

Fernald, R. D. and Hirata, N. R. (1977). Field study of Haplochromis burtoni: quantitative behavioral observations. Anim. Behav. 25, 964-975

Fernald, R. D. and Shelton, L. C. (1985). The organization of the diencephalon and the pretectum in the cichlid fish, Haplochromis burtoni. J. Comp. Neurol. 238, 202217.

Filby, A. L., Paull, G. C., Bartlett, E. J., Van Look, K. J. and Tyler, C. R. (2010). Physiological and health consequences of social status in zebrafish (Danio rerio). Physiol. Behav. 101, 576-587.

Fox, H. E., White, S. A., Kao, M. H. and Fernald, R. D. (1997). Stress and dominance in a social fish. J. Neurosci. 17, 6463-6469.

Frischknecht, H., Siegfried, B. and Waser, P. G. (1982). Learning of submissive behavior in mice: a new model. Behav. Processes 7, 235-245.

Gil, G. A., Silvestre, D. C., Tomasini, N., Bussolino, D. F. and Caputto, B. L. (2012). Controlling cytoplasmic c-Fos controls tumor growth in the peripheral and central nervous system. Neurochem. Res. 37, 1364-1371.

Gilmour, K. M., Dibattista, J. D. and Thomas, J. B. (2005). Physiological causes and consequences of social status in salmonid fish. Integr. Comp. Biol. 45, 263-273.

Goodson, J. L. (2005). The vertebrate social behavior network: evolutionary themes and variations. Horm. Behav. 48, 11-22.

Goodson, J. L. and Bass, A. H. (2002). Vocal-acoustic circuitry and descending vocal pathways in teleost fish: convergence with terrestrial vertebrates reveals conserved traits. J. Comp. Neurol. 448, 298-322.

Goodson, J. L. and Kabelik, D. (2009). Dynamic limbic networks and social diversity in vertebrates: from neural context to neuromodulatory patterning. Front. Neuroendocrinol. 30, 429-441.

Goodson, J. L., Kelly, A. M., Kingsbury, M. A. and Thompson, R. R. (2012). An aggression-specific cell type in the anterior hypothalamus of finches. Proc. Natl. Acad. Sci. USA 109, 13847-13852.

Grosenick, L., Clement, T. S. and Fernald, R. D. (2007). Fish can infer social rank by observation alone. Nature 445, 429-432.

Hofmann, H. A. and Fernald, R. D. (2000). Social status controls somatostatin neuron size and growth. J. Neurosci. 20, 4740-4744.

Hofmann, H. A., Benson, M. E. and Fernald, R. D. (1999). Social status regulates growth rate: consequences for life-history strategies. Proc. Natl. Acad. Sci. USA 96 14171-14176.

Kirschbaum, C. and Hellhammer, D. H. (1989). Salivary cortisol in psychobiological research: an overview. Neuropsychobiology 22, 150-169.

Kollack-Walker, S., Watson, S. J. and Akil, H. (1997). Social stress in hamsters: defeat activates specific neurocircuits within the brain. J. Neurosci. 17, 8842-8855.

Kollack-Walker, S., Don, C., Watson, S. J. and Akil, H. (1999). Differential expression of c-fos mRNA within neurocircuits of male hamsters exposed to acute or chronic defeat. J. Neuroendocrinol. 11, 547-559.

Kovács, K. J. (1998). c-Fos as a transcription factor: a stressful (re)view from a functional map. Neurochem. Int. 33, 287-297.

Kustan, J. M., Maruska, K. P. and Fernald, R. D. (2012). Subordinate male cichlids retain reproductive competence during social suppression. Proc. Biol. Sci. 279, 434 443.

Larson, E. T., O'Malley, D. M. and Melloni, R. H., Jr (2006). Aggression and vasotocin are associated with dominant-subordinate relationships in zebrafish. Behav. Brain Res. 167, 94-102.

Lee, Y. N., Tuckerman, J., Nechushtan, H., Schutz, G., Razin, E. and Angel, P. (2004). c-Fos as a regulator of degranulation and cytokine production in FcepsilonRl-activated mast cells. J. Immunol. 173, 2571-2577.

Leshner, A. I. (1980). The interaction of experience and neuroendocrine factors in determining behavioral adaptations to aggression. In Progress in Brain Research, Vol. 53 (ed. P. S. McConnell), pp. 427-438. Amsterdam: Elsevier.

Lin, D., Boyle, M. P., Dollar, P., Lee, H., Lein, E. S., Perona, P. and Anderson, D. J. (2011). Functional identification of an aggression locus in the mouse hypothalamus. Nature $\mathbf{4 7 0}, \mathbf{2 2 1 - 2 2 6 .}$

Maddox, S. A., Monsey, M. S. and Schafe, G. E. (2011). Early growth response gene $1(E g r-1)$ is required for new and reactivated fear memories in the lateral amygdala. Learn. Mem. 18, 24-38.

Malkani, S., Wallace, K. J., Donley, M. P. and Rosen, J. B. (2004). An egr-1 (zif268) antisense oligodeoxynucleotide infused into the amygdala disrupts fear conditioning Learn. Mem. 11, 617-624.

Martinez, M., Calvo-Torrent, A. and Herbert, J. (2002). Mapping brain response to social stress in rodents with c-fos expression: a review. Stress 5, 3-13.

Maruska, K. P. and Fernald, R. D. (2010a). Behavioral and physiological plasticity: rapid changes during social ascent in an African cichlid fish. Horm. Behav. 58, 230240.

Maruska, K. P. and Fernald, R. D. (2010b). Reproductive status regulates expression of sex steroid and $\mathrm{GnRH}$ receptors in the olfactory bulb. Behav. Brain Res. 213, 208-217.

Maruska, K. P. and Fernald, R. D. (2010c). Steroid receptor expression in the fish inner ear varies with sex, social status, and reproductive state. BMC Neurosci. 11 58

Maruska, K. P. and Fernald, R. D. (2011a). Social regulation of gene expression in the hypothalamic-pituitary-gonadal axis. Physiology 26, 412-423. 
Maruska, K. P. and Fernald, R. D. (2011b). Plasticity of the reproductive axis caused by social status change in an african cichlid fish: II. Testicular gene expression and spermatogenesis. Endocrinology 152, 291-302.

Maruska, K. P. and Fernald, R. D. (2012). Contextual chemosensory urine signaling in an African cichlid fish. J. Exp. Biol. 215, 68-74.

Maruska, K. P. and Fernald, R. D. (2014). Social regulation of gene expression in the African cichlid fish Astatotilapia burtoni. In The Oxford Handbook of Molecular Psychology (ed. T. Canli). New York: Oxford University Press (in press)

Maruska, K. P., Levavi-Sivan, B., Biran, J. and Fernald, R. D. (2011). Plasticity of the reproductive axis caused by social status change in an African cichlid fish: I. Pituitary gonadotropins. Endocrinology 152, 281-290.

Maruska, K. P., Ung, U. S. and Fernald, R. D. (2012). The African cichlid fish Astatotilapia burtoni uses acoustic communication for reproduction: sound production, hearing, and behavioral significance. PLOS ONE 7, e37612.

Maruska, K. P., Zhang, A., Neboori, A. and Fernald, R. D. (2013). Social opportunity causes rapid transcriptional changes in the social behaviour network of the brain in an African cichlid fish. J. Neuroendocrinol. 25, 145-157.

Matter, J. M., Ronan, P. J. and Summers, C. H. (1998). Central monoamines in freeranging lizards: differences associated with social roles and territoriality. Brain Behav. Evol. 51, 23-32.

Maximino, C., Lima, M. G., Oliveira, K. R., Batista, E. J. and Herculano, A. M. (2013). 'Limbic associative' and 'autonomic' amygdala in teleosts: a review of the evidence. J. Chem. Neuroanat. 48-49, 1-13.

McDade, D. M., Conway, A. M., James, A. B. and Morris, B. J. (2009). Activitydependent gene transcription as a long-term influence on receptor signalling. Biochem. Soc. Trans. 37, 1375-1377.

McEwen, B. S. and Seeman, T. (1999). Protective and damaging effects of mediators of stress. Elaborating and testing the concepts of allostasis and allostatic load. Ann N. Y. Acad. Sci. 896, 30-47.

Morrison, K. E., Curry, D. W. and Cooper, M. A. (2012). Social status alters defeatinduced neural activation in Syrian hamsters. Neuroscience 210, 168-178.

Mueller, T. and Guo, S. (2009). The distribution of GAD67-mRNA in the adult zebrafish (teleost) forebrain reveals a prosomeric pattern and suggests previously unidentified homologies to tetrapods. J. Comp. Neurol. 516, 553-568.

Munoz-Cueto, J. A., Sarasquete, C., Zohar, A. H. and Kah, O. (2001). An Atlas Of The Brain Of The Gilthead Seabream (Sparus aurata). College Park, MD: Maryland Sea Grant.

Neumann, I. D. (2002). Involvement of the brain oxytocin system in stress coping interactions with the hypothalamo-pituitary-adrenal axis. Prog. Brain Res. 139, 147162

Newman, S. W. (1999). The medial extended amygdala in male reproductive behavio A node in the mammalian social behavior network. Ann. N. Y. Acad. Sci. 877, 242257

O'Connell, L. A. and Hofmann, H. A. (2011). The vertebrate mesolimbic reward system and social behavior network: a comparative synthesis. J. Comp. Neurol. $\mathbf{5 1 9}$ 3599-3639.

O'Connell, L. A. and Hofmann, H. A. (2012). Evolution of a vertebrate social decision-making network. Science 336, 1154-1157.
Overli, O., Harris, C. A. and Winberg, S. (1999). Short-term effects of fights for social dominance and the establishment of dominant-subordinate relationships on brain monoamines and cortisol in rainbow trout. Brain Behav. Evol. 54, 263-275.

Øverli, O., Kotzian, S. and Winberg, S. (2002). Effects of cortisol on aggression and locomotor activity in rainbow trout. Horm. Behav. 42, 53-61.

Øverli, O., Sørensen, C., Pulman, K. G., Pottinger, T. G., Korzan, W., Summers, C. H. and Nilsson, G. E. (2007). Evolutionary background for stress-coping styles: relationships between physiological, behavioral, and cognitive traits in nonmammalian vertebrates. Neurosci. Biobehav. Rev. 31, 396-412.

Pagel, J. I. and Deindl, E. (2011). Early growth response 1 - a transcription factor in the crossfire of signal transduction cascades. Indian J. Biochem. Biophys. 48, 226-235.

Parikh, V. N., Clement, T. and Fernald, R. D. (2006a). Physiological consequences of social descent: studies in Astatotilapia burtoni. J. Endocrinol. 190, 183-190.

Parikh, V. N., Clement, T. S. and Fernald, R. D. (2006b). Androgen level and male social status in the African cichlid, Astatotilapia burtoni. Behav. Brain Res. 166, 291 295.

Pérez-Cadahía, B., Drobic, B. and Davie, J. R. (2011). Activation and function of immediate-early genes in the nervous system. Biochem. Cell Biol. 89, 61-73.

Pinaud, R., Velho, T. A., Jeong, J. K., Tremere, L. A., Leão, R. M., von Gersdorff, H. and Mello, C. V. (2004). GABAergic neurons participate in the brain's response to birdsong auditory stimulation. Eur. J. Neurosci. 20, 1318-1330.

Robinson, G. E., Fernald, R. D. and Clayton, D. F. (2008). Genes and social behavior. Science 322, 896-900.

Sapolsky, R. M. (2005). The influence of social hierarchy on primate health. Science 308, 648-652.

Schippert, R., Schaeffel, F. and Feldkaemper, M. P. (2009). Microarray analysis of retinal gene expression in Egr-1 knockout mice. Mol. Vis. 15, 2720-2739.

Summers, C. H. (2002). Social interaction over time, implications for stress responsiveness. Integr. Comp. Biol. 42, 591-599.

Summers, C. H., Forster, G. L., Korzan, W. J., Watt, M. J., Larson, E. T., Overli, O., Höglund, E., Ronan, P. J., Summers, T. R., Renner, K. J. et al. (2005). Dynamics and mechanics of social rank reversal. J. Comp. Physiol. A 191, 241-252.

Tamashiro, K. L., Nguyen, M. M. and Sakai, R. R. (2005). Social stress: from rodents to primates. Front. Neuroendocrinol. 26, 27-40.

Tokarz, R. R. (1987). Effects of corticosterone treatment on male aggressive behavior in a lizard (Anolis sagrei). Horm. Behav. 21, 358-370.

White, S. A., Nguyen, T. and Fernald, R. D. (2002). Social regulation of gonadotropin-releasing hormone. J. Exp. Biol. 205, 2567-2581.

Winberg, S., Winberg, Y. and Fernald, R. D. (1997). Effect of social rank on brain monoaminergic activity in a cichlid fish. Brain Behav. Evol. 49, 230-236.

Wullimann, M. F. and Mueller, T. (2004). Teleostean and mammalian forebrains contrasted: evidence from genes to behavior. J. Comp. Neurol. 475, 143-162.

Zhao, S. and Fernald, R. D. (2005). Comprehensive algorithm for quantitative realtime polymerase chain reaction. J. Comput. Biol. 12, 1047-1064.

Zhou, H., Gao, J., Lu, Z. Y., Lu, L., Dai, W. and Xu, M. (2007). Role of c-Fos/JunD in protecting stress-induced cell death. Cell Prolif. 40, 431-444.

Zink, C. F., Tong, Y., Chen, Q., Bassett, D. S., Stein, J. L. and Meyer-Lindenberg, A. (2008). Know your place: neural processing of social hierarchy in humans. Neuron 58, 273-283. 